\title{
Do Squirrels Eat Hamburgers? Intellectual Empathy as a Remedy for Residual Prejudice
}

\author{
MAUREEN LINKER
}

Department of Literature, Philosophy, and the Arts

University of Michigan-Dearborn

4901 Evergreen Road

Dearborn, MI 48128

U.S.A.

mlinker@umd.umich.edu

\begin{abstract}
In this essay, I argue the value of integrating aspects of social identity theory with informal logic generally. Interpretation and judgment can break break down in rhetorical contexts where social differences are significant. This is often the result of "residual prejudice" (Fricker, 2007) and unconscious bias. Using several examples from a study on classroom dialogue in an inner city Midwestern elementary school, I show how bias was the result of unreflective and unconscious social attitudes. I propose a 4 stage process of "intellectual empathy" as a route to more socially reflective thinking, drawing on the strengths of informal logic and social theory.
\end{abstract}

Resumé: Dans cet essai, je défens une intégration des aspects de la théorie d'identité sociale avec la logique non formelle en général. L'interprétation et le jugement peuvent faire échec dans des contextes rhétoriques lorsque des différences sociales sont importantes. Ceci est souvent le résultat d'un «préjudice résiduel» (Fricker, 2007) et d'une partialité inconsciente. À l'aide de plusieurs exemples tirés d'une étude sur le dialogue en salle de classe d'une école élémentaire dans une ville du Midwest, je montre comment cette partialité était le résultat d'attitudes sociales irréfléchies et inconscientes. Je puise dans les contributions de la logique non formelle et de la théorie sociale pour proposer un processus de quatre étapes de «empathie intellectuelle» comme un moyen pour atteindre une pensée plus socialement réfléchie.

Keywords: bias, Fricker, Lippman, prejudice, reflective thinking, rhetoric, social epistemology, stereotyping

\section{Introduction}

In his book Thinking in Education, Matthew Lippman argues that classroom dialogue in most North American primary and 
secondary schools offers little opportunity for teachers and students to engage in "reflective thinking" (Lippman 2003). Lippman describes reflective thinking in the following way:

Reflective thinking takes into account its own methodology, its own procedures, its own perspective, and its own point of view. Reflective thinking is prepared to recognize the factors that make for bias, prejudice, and self-deception. It involves thinking about its own procedures at the same time thinking about its own subject matter. In deliberative inquiry in the classroom there must be continual awareness of the importance of methodology of such inquiry all the while that matters of substance are being discussed. It is because this is so seldom the case that bias and self-deception so frequently have free rein in classroom argumentation. The conversation is a ventilation of prejudices rather than deliberative inquiry. (26)

Lippman attributes the lack of reflective thinking in the classroom to the chokehold that state and government assessment measures have on curriculum as well as the pervasive authority of textbooks designed to meet these measures. His proposal to remedy the lack of reflective thinking is to add applied philosophy to the elementary and secondary school curriculum. In particular, Lippman traces the evolution of critical thinking and informal logic as the kind of applied philosophy that would prove to be a valuable route to transforming curriculum and classroom dialogue. He writes:

In the late 1970s a dissident group of logicians had been calling for a logic that was more attuned to natural language and that would be better adapted than classical or symbolic logic to help students reason more effectively. Towards this end, a conference was held at the University of Windsor in Canada in 1978, and this in turn produced the Newsletter of Informal Logic (later to become the Journal of Informal Logic). The group was concerned with everything from theoretical issues of fallacy and argument to practical issues to pedagogical questions (how to design critical thinking courses; what sorts of materials should be used). Informal logic in philosophy is now in a very productive phase, with a considerable number of publications every year and with a continuing affirmation of its kinship to critical thinking. (41)

Yet Lippman is dissatisfied with most of what the education community has assimilated from informal logic and critical thinking. He argues that throughout the 1980s and 1990s while critical thinking texts were making their way into seasonal teacher training catalogues most of the books adopted were roughly identical and focused on basic classroom exercises with 


\section{Maureen Linker}

very little of the substantive theory on communal learning and self-reflective practice that was more prevalent in the philosophical informal logic community. (Lippman notes for example that: "There were still some hopeful signs. The journal Informal Logic always a paragon of integrity devoted a portion of each issue to matters of teaching." (p. 45))

Lippman's emphasis on the reflective aspects of critical thinking is well-founded. While he does consider a variety of authoritative definitions and conceptions of critical thinking including impartiality, accuracy, carefulness, clarity, truthfulness, abstraction, coherency, and practicality (p. 58) he defends the priority of self-reflection in a communal dialogue. While I agree with much of Lippman's analysis and conclusion I would argue that there is an important element missing in his account of reflective critical thinking and it is missing as well in much of the research and scholarship that has come out of the philosophical informal logic community. The element I have in mind is a rhetorical framing that makes sense of social location and the corresponding social matrix of privilege, power, difference, and disadvantage. From my own experience teaching critical thinking at the college level and more recently, from participating in research at the elementary school level, it is evident that in cases where social power, privilege, and disadvantage are operative there is a need for rhetorical analysis that can reduce the "ventilation of prejudice" in the classroom and instead promote the kind of "deliberative inquiry" and essential reflective thinking called for by Lippman.

While Lippman argues that not enough textbooks offer theoretical insight into the reflective aspects of critical thinking, he does not specifically address the need to be self-reflective about race, class, gender, sexual orientation, and social class. Lippman's omission is consistent with most of the textbooks in critical thinking and informal logic. While many provide students and instructors with a wealth of examples of fallacious reasoning, emotive uses of language, standards for judging the credibility of speakers and methods for analyzing the acceptability of their claims, they offer little in the way of social difference, advantage, or disadvantage. Along the same lines, while many texts reference controversial moral, social, and political issues such as abortion, gay marriage, or voter fraud, most do not address the biased elements within an individual's system of belief or an individual's standing with regard to social power and social hierarchies. ${ }^{1}$

\footnotetext{
${ }^{1}$ A notable exception is Wanda Teays's Second Thoughts: Critical Thinking for a Diverse Society, McGraw-Hill, 2005.
} 
For instance, in Moore and Parker's text Critical Thinking (2008), students have the opportunity to evaluate arguments for or against gay marriage (pp. 484-486) but are offered no real methods for how to consider the centrality of heterosexuality in their own thinking and in the wider culture. When a heterosexual student rebuts arguments for equal opportunity and protection for homosexuals because they see this as an effort by the homosexual community to gain "special rights," the student may be failing to recognize the daily injustices many homosexuals face in their inability to legally, publically and safely identify as a "real" couple or family. Similarly, the heterosexual student may not see the social privilege inherent in her ability to publically show her affection to her boyfriend, choose whether or not to marry, or eventually and safely identify as a "family." Rather, the student most likely engages in these actions unreflectively and treats them as merely "normal" features of her "everyday", life." The difficulty that most of us have with seeing how others are socially disadvantaged at the expense of our social advantages is described by social theorists as "the obliviousness of privilege" (McIntosh 1999, Johnson 2005).

Most of the work on social identity, privilege, power, and disadvantage comes out of scholarship in sociology, feminist theory and postcolonial studies (McIntosh 1988, 1999, Crenshaw et al. 1995, Adams 2000, Wise 2004, Hooks 2009, Anderson \& Middleton 2010). Research by scholars in these fields has resulted in complex analyses about how perspective is rooted not simply in individual space-time location but in complex aspects of social location and unexamined social advantages. This more social aspect to perspective I argue, is needed in informal logic specifically because it can aid in the best reflective elements of good critical thinking and rhetorical analysis. Similarly, the very best elements of informal logic theory should make their way into social identity theory so that scholars and students can see how many systems of interlocking oppression and injustice are often the result of non-impartial, inaccurate, inconsistent, and non-reflective mistakes in reasoning. In many cases, the individuals or groups who engage in this kind of oppressive or unjust thinking are not even aware of their mistakes.

Along these lines epistemologist Miranda Fricker (2007) argues that many insights into judgments about credibility, reliable testimony, and rationality are lost if we fail to face the complexities of social difference, privilege, power, and disadvantage. Fricker's argument does not deny the value of traditional methods in epistemology particularly those that abstract from relations of social power to get at fundamental aspects of belief formation and justification. Rather, her view is that such methods may be all too limited in cases where bias, prejudice, 


\section{Maureen Linker}

and cultural assumptions are tacitly and unreflectively incorporated into an individual's or a group's system of beliefs. In particular, Fricker notes that it is "the silent by-products of residual prejudice in a liberal society" that are the most difficult to uncover (Fricker, p. 58). Iris Marion Young characterizes this difficulty as "the disadvantage and injustice some people suffer not because a tyrannical power intends to keep them down, but because of a well intentioned liberal society" (Young 1992, p. 26).

The well-intentioned liberal society that Fricker and Young refer to includes all those in positions of leadership who would like to see everyone have the opportunity to succeed. Yet many of these same leaders may fail to see how pointing everyone in the direction of success may require that those who are less advantaged socially forego their own credibility and their own experiences. In addition, success is often measured and defined according to the norms and standards of those who are most socially advantaged. Rather than seeing these norms and standards as socially and culturally constructed, they are taken as objective and promoted by those who benefit as benignly good or right. Success then requires that those who are socially disadvantaged forego their own system of beliefs, experiences and observations so as to measure up to these less than objective standards. Such a sacrifice is not only unfair but also works against basic principles of critical thinking and good reasoning.

In what follows I present a variety of cases where unreflective, residual prejudice is operative in teacher-student dialogues in an elementary classroom. I emphasize that in these cases, the teachers involved were well intentioned, seemingly non-biased against their students, and certain that what they were doing was best for their students in the tradition of liberalism described above. After outlining the cases and offering an assessment I turn to a proposal to remedy the residual bias that occurred through the development of a rhetorical principle of "intellectual empathy." The proposal has four component features and I discuss each in turn. Finally, I conclude that the incorporation of a more socially complex perspective in informal logic combined with a principle of intellectual empathy, could be a path to more reflective classroom dialogue and more overall effective critical thinking.

\section{Do squirrels eat hamburgers?}

The "Tanglewood" district is located in a major metropolitan area in the Midwest region of the United States. It is comprised of three elementary schools, a middle school and a high school. Tanglewood teachers and administrators are predominantly 
white. Seventy-three percent of the student population is African-American, 24\% Caucasian, 1.4\% Hispanic, 1\% Asian, and less than one percent American Indian. Approximately $88 \%$ of the student population is eligible for free and reduced lunch. All three elementary schools are classified as Title I meaning that a statistically significant number of the student population is at or below the poverty line. The district has struggled with low standardized test scores in the critical areas of math, science, reading, and writing.

A collaborative partnership between my university and the district developed over the past five years as an outgrowth of interactions between a small group of Tanglewood teachers and university professors working on a variety of unrelated projects ${ }^{2}$. Common to all of these interactions were conversations about the practice and context of teaching in high poverty schools and how to best teach the students in Tanglewood. The more cohesive project developed in stages. The first stage involved an effort to collect data on student conceptions of school and its importance for the future goals of students. During the 2006-2007 school year, data were obtained from district wide interviews with 28 teachers and four administrators, classroom observations, and focus group interviews with approximately 80 elementary students in 8 classrooms. After an initial analysis of the data, teachers and administrators were invited to participate in a two-day workshop in the summer of 2007. Thirteen teachers participated. The focus was on local community and students' out of school experiences in order to develop more meaningful lessons. The group also considered one specific finding from the data analysis; a majority of the students, 72\% said that school was unimportant in their lives and that they felt insignificant and unimportant as individuals in school. Following the summer group, five fifth grade teachers and their students volunteered to continue collaboration with the university faculty during the 2008-2009 school year to work on developing lesson plans that would align with curriculum and integrate content whenever feasible so as to deepen students' learning.

There was a general concern by the university professors in the group that the content, cultural norms, and shared experiences evident in the state curriculum materials reflected the middle-class, predominantly white district where they were developed. For example, for language arts students were asked to write letters in response to prompts that dealt with summer camp, home ownership, and community resources that are not available in Tanglewood. Initially some teachers blamed the

\footnotetext{
${ }^{2}$ For a more detailed account of the larger research project see Burke, Adler \& Linker (2007).
} 
students by ascribing their difficulties with the writing prompts to a lack of skills, general background knowledge, and/or lack of interest in the stories. Others recognized that their students might lack the relevant experiences to make sense of these prompts because they were well aware of poverty, hunger, neglect, and stress in the lives of their students. Yet, many of these same teachers knew very little about the particular aspects of the community in which the children lived. For that reason they were hesitant to propose curricular changes that might be more culturally relevant for the students.

I was invited into this collaboration by a colleague in the School of Education because of some research I had done previously on the social dimensions of rationality and reason as well as my experience teaching critical thinking at the college level ${ }^{3}$. The group was interested in the question "Could a curriculum be developed that was more localized and culturally relevant while still meeting general standards for achievement?" I was asked to participate in the classroom observations and teacher interviews and attend the two-day summer workshop with teachers all the while attending to aspects of critical thinking including rhetorical context, fallacies, emotive uses of language, stereotyping, and bias. My role was to document teacher/student dialogues with special attention to how the dialogues might generate a more equitable, culturally sensitive, and "empowering" level of discourse for students in the Tanglewood elementary schools.

A concern for the whole working group was the question of whether there were factors in the classroom experience that were contributing to the students' sense of alienation and lack of identification with school. Through my participation in the project I came to see that significant rhetorical problems were in many cases the result of failures on the part of those in a position of authority to examine their own beliefs, biases, and assumptions regarding social power and disadvantage.

For example, sometime during the second week of the project I sat in on a third grade science lesson having to do with "habitats." The teacher began by asking the class "What do squirrels eat?" One boy in the class raised his hand and when the teacher asked him to respond he shouted out "Hamburgers!" Some of the kids in the class giggled and the teacher smiled patiently. "Do you really think squirrels eat hamburgers?" she asked with just a hint of disbelief in her voice. The boy looked at her and his expression was earnest. "I saw a squirrel eating a hamburger in the dumpster behind McDonalds." His tone was insistent. The teacher smiled and said, "That was an unusual case. Now what do you think most squirrels eat in their natural

\footnotetext{
${ }^{3}$ Linker (2001) and Linker (2003).
} 
habitat?" Eventually, the students come up with the answer the teacher was looking for; squirrels eat nuts, seeds, and acorns that they find in the woods.

After the class I had the chance to talk with the teacher. I pointed out that the answer the boy offered, from the perspective of evidence and justification, was a good one. The boy relied upon his own first hand observation and recounted a relevant experience to answer the question. I added that squirrels from what I knew, are scavengers and live naturally in urban, suburban, and rural settings. To distinguish suburban or rural settings as "natural" and urban settings as "unnatural" seemed to imply that cities are neither safe nor healthy places for living things. The teacher nodded and said she understood my points. Yet when I got to the end of my comments she said "Well that's all very interesting but I have to prepare these kids to pass state standardized tests and believe me, when the question comes up as to what squirrels eat, one of the choices will not be hamburgers!"

I understood the teacher's point as well although from a purely pragmatic point of view. If she wants this boy to succeed, and she does, then it is her job to steer him in the direction of correct answers for upcoming tests. Yet the dismissal of the boy's response results in a two-fold loss. First, he receives the message that his ability to provide relevant data from his own experience may be inconsequential to succeeding academically. And secondly, the dismissal could result in a loss to his sense of self. As Fricker notes:

To be wronged in one's capacity as a knower is to be wronged in a capacity essential to human value... The capacity to give knowledge to others is one side of the many-sided capacity so significant in human beings; namely, the capacity for reason. We are long familiar in the history of Western philosophy, that our rationality is what lends our humanity its distinctive value. No wonder, then, that being undermined or otherwise wronged in one's capacity as a giver of knowledge is something that can cut so deep. (Fricker 2007, p. 44.)

The literature in education theory corroborates Fricker's point. For instance in a recent study on white teachers' perceptions of students, Black children in particular were perceived as less competent and less knowledgeable by teachers and teachers in training (Parks \& Kennedy, 2007). The result of this study was consistent with earlier studies done in the 1960s and 1970s and was surprising to researchers because diversity training has become a regular part of teacher training programs throughout 
education curricula at both the undergraduate and graduate level. But as the authors of the 2007 study note:

Just because students are exposed to a concept does not mean they will incorporate it into their teaching and practice. Teachers are surely aware through their training and prior research that stereotypical thinking can have very detrimental effects in the classroom and on students' self esteem; they must become more cognizant of their own biases and in turn reduce them. We suggest that more training programs be implemented including practical application related to one's own teaching style and goals. (pp. 941-942.)

The stereotypes in both the teacher's beliefs and in the expectations on standardized tests, rather than providing opportunities for this boy to reason well instead sacrifice his reasoning abilities and perhaps even his sense of self. The boy is being directed toward meeting standards for academic success that are inconsistent with empirical data and his own direct first hand experience.

The teacher too in this case sees the loss but it does not outweigh her priority to prepare this boy to do well on assessment measures. The teacher's prioritizing too comes from some very good intentions. In fact in the six or so months that I spent getting to know many of the teachers in the district I could see how well intentioned they were. They wanted these children to succeed. They wanted the school administration to succeed. And many of the teachers cared deeply for their students. They were truly concerned about the high drop out rates in the district and the low numbers of children succeeding academically. On their own time and with their own money, the teachers bought coats, mittens, and notebooks for students who were in need. And they spent countless hours and lots of emotional energy getting to know the particularities of their students' hopes and fears. They were, it is worth repeating, very well intentioned people.

Yet despite the hard work and attention the teachers gave to these students there were some clear gulfs between them. Most of the students were living in poverty. The majority were African American. Most of the teachers were middle class and white. While the teachers had tremendous concern and compassion for their students, their feelings about the children's parents were an entirely different matter. In workshops and breakout sessions with the teachers, it became clear to me and the other members of our group that the teachers were enormously frustrated with the parents. Their frustration was the result of a variety of factors including parents not signing necessary forms and returning them to school, to children not going to bed early 
enough in the evening, to parents being late to pick children up at school. There was little parental involvement in school organizations and teachers complained that when they held school events, parents rarely showed.

So while the teachers worked hard to educate and care for the students in their school the reaction they had toward parents had a very different quality. The differences between teacherstudent relationships and teacher-parent relationships was apparent in some of the judgments and choices the teachers made regarding the children and their home lives. One of the characteristics of these judgments was that they lacked some basic principles of good reasoning that the teachers' could easily employ in most other rhetorical contexts.

For instance, during a workshop one teacher reported that she had to drive one of her students home because the boy's mother did not have access to a car at the time. The teacher explained that after she dropped the child off the mother set him up in front of the television and then went in to the kitchen to take a forty-ounce beer out of the fridge. As the teacher prepared to leave the mother came out on to the front steps of the house to thank her and say goodbye and then the teacher said "... and then she just sat there on the front porch drinking out of the bottle!" The other teachers shook their heads in disapproval as they listened to this account. Yet later in the day after the workshop had ended, the very same teacher was packing up her bags and remarked "Ah...what a long day. I can't wait to get home, pour myself a glass of wine, and sit in the backyard and relax." Many of the other teachers nodded their heads in agreement or added comments of approval. When it was pointed out at the next meeting that the choice to go home at the end of the day and have a glass of wine in the backyard was not unlike the choice to have a beer on the front steps, the teachers resisted the analogy. As the discussion continued many struggled to articulate why they found a significant qualitative difference between drinking wine versus beer and doing so on your front steps versus your backyard. When it was suggested that perhaps it was a difference in social class the teachers had a hard time distinguishing their middle class norms from what was just simply "normal" or "right." Because so much in their social and cultural experience reaffirmed their choices as the right or expected choices they failed to see the analogy with their own behavior and the behavior of the working class woman of color.

It was not that these teachers were incapable of analogical reasoning, rather it seems that their ability to see the relevant similarities was impeded by their "obliviousness about privilege." McIntosh writes, "Obliviousness about social advantage is kept strongly inculturated in the United States so as to main- 
tain the myth of meritocracy, the myth that democratic choice is equally available to all. Remaining unaware that freedom of confident action is there for just a small number of people props up those in power and serves to keep power in the hands of the same groups that have most of it already" (McIntosh, p. 351).

A more "socially situated" account of belief, reason, and knowledge would incorporate the variety of social factors that are at play in the teacher's initial inability to see the analogy. The case illustrates why in some circumstances an attention to social difference and power is crucial to assessing obstacles in the way of good reasoning. Particularly in circumstances where well-intentioned people believe that they are simply "doing the right thing" or "making the right judgment" it is difficult to motivate effective self-criticism related to power dynamics and social standards. Yet a lack of motivation can result in epistemic losses to the particular individual making the judgment. The teacher for example failed to account for relevant data and as a result loses the opportunity to add up her beliefs and her judgments in coherent and consistent ways. Further, a loss is incurred by the parents being judged since their reasonableness and credibility, and in some sense their humanity, are unfairly undermined. The case illustrates the various power differentials at work, namely the differences in power between teachers and students and teachers and parents. There are also clear social differentials at work including race, class, and education level. Without attention to and an analysis of these differences, the obstacles to good reasoning would remain obscure.

\section{Standing in relations of social power}

A socially situated account of a human practice is an account such that the participants are not conceived in abstraction from relations of social power (as they are in traditional epistemology) but as operating as social types who stand in relations of power to one another.... Many philosophical questions may be best served by the traditional, maximally abstracted conception of the human subject, but confining oneself to that conception restricts the sort of philosophical questions and insights one can come up with, so that the philosophical repertoire incurs a needless impoverishment. Ultimately, the point is to see how our epistemic conduct might become at once more rational and more just. (Fricker, 2007, pp. 3-4.)

Fricker argues that a failure to take power dynamics into consideration in epistemic contexts can result in our being less than rational and in some cases, unjust. It was clear what a struggle it was for many of the teachers we worked with to have to face 
their own obliviousness to power and privilege in the classroom. The reason for this difficulty is that individuals who benefit from social power or privilege experience it as "normal" rather than as any kind of advantage. For instance, as a married heterosexual, I think nothing of holding hands on the street when I walk with my spouse or displaying photos of us together on my desk at work because these actions seem simply "normal" to me and hence not much of a big deal. However, if I was homosexual and living with my partner, I may have some serious second thoughts about holding hands or walking arm in arm with my partner or displaying romantic photographs in my office. The social privilege and power of heterosexuality in our culture is not experienced by heterosexuals as advantage but simply as the way things are. For that reason it is very difficult for those who benefit from social advantages to see them as anything other than the status quo.

When groups who experience social disadvantages argue for their experiences and their rights to be recognized, it can feel to those who already have social advantages that these groups want "special recognition" or "special rights." This kind of thinking became apparent in our group when the recommendation came up for teachers to use examples in the classroom that were more personally relevant to the students. The recommendation came after one of my colleagues sat through a fourth grade writing exercise in which the teacher used questions to prompt story writing. The teacher began by modeling a brainstorming session in which she asked herself; "Where would I like to go on vacation?" Her response was "Hawaii!" She then asked the children to offer suggestions for things she might do in Hawaii. There were mostly murmurs and vague offerings like "surfing?" or "swimming?" It was clear to my colleague that the students were not engaged and had a hard time coming up with specific answers. The teacher talked about luaus and ukulele music and was met with mostly blank stares. One student remarked that the Disney movie "Lilo and Stich" had something to do with Hawaii. Yet our group had interviewed the students prior to our being in the classroom and the data showed that the students' favorite activities included playing basketball, listening to rap and hip hop music, having cookouts with their extended family, and going to the movies. We had shared the data with the teachers in the hope that it might frame classroom examples to engage the students more directly. However we were told flatly by several teachers that using examples involving basketball or hip hop music with children of color was "stereotypical" and "demeaning" even though the data showed that these were some of the children's primary interests. 
In other words, the teachers who were mostly white, middle class and college educated were oblivious to how their choices as to what constituted "non-stereotypical," acceptable activities were relative to a set of social and cultural standards indicative of power and privilege. The one teacher's inability to see the analogy between her choice to relax with a glass of wine in the backyard and the mother who chose to relax on her front steps with a beer was the result of taking one set of culturally acceptable practices as the norm. Everything in the teachers experiences from their upbringing, to the popular images in the media, to their professional experiences reaffirmed their sense of "normal" and "acceptable" and discounted different experiences that went beyond that framework. The teachers' resistance to using examples culled from the lives of the children was based on their sense that they would be negatively stereotyping the children by including rap music and basketball as relevant classroom examples. This belief did not allow them to see that vacationing in Hawaii and going surfing were also representative of another set of stereotypes though ones they deemed positive and appropriate. As a result the children had to work around the unfamiliarity of the examples and were once again given the message that their experiences were not relevant to the content of the academic discourse.

\section{Developing "intellectual empathy"}

Thus far I have argued that well-intentioned individuals who are typically capable of non-fallacious, relevant, analogical reasoning may nevertheless fail to employ those same skills in rhetorical contexts where social difference is a factor. The reason for the failure, I maintain, is the result of residual prejudice and the invisibility of the social types who as Fricker says, "stand in relations of power to one another" (p. 4). The failure results in a variety of losses including epistemic and evidential losses, moral and existential losses particularly to those who are socially marginalized in the context, and the loss of reflective thinking that might point the way to solving problems of social inequality.

In the remainder of this paper I will sketch out a principle I refer to here as "intellectual empathy" as a solution for the kind of residual bias outlined thus far. I intend the principle as a starting point in dialogues, debates, and arguments around issues of social identity and social difference. Similar to the "Principle of Charity" or a "Presumption in Favor" I propose the "Principle of Intellectual Empathy" as a set of interpretive assumptions with the goal of maximizing meaningful discourse and minimizing the effects of residual prejudice. The Principle as I outline it 
here has four methodological aspects and I will describe each in turn. However, before doing so, I would like to first provide some background for the role that "empathy" plays more generally in the principle.

\subsection{Empathy as a fully developed cognitive capacity}

Empathy is the capacity to put oneself in the shoes of othersnot just individuals, but whole categories of people: one's countrymen, those in other countries, other living beings, especially those who are in some way oppressed, threatened, or harmed. Empathy is the capacity to care, to feel what others feel, to understand what others are facing and what their lives are like. Empathy extends well beyond feeling to understanding, and it extends beyond individuals to groups, communities, peoples, even species. Empathy is at the heart of real rationality, because it goes to the heart of our values, which are the basis of our sense of justice. (Lakoff 2009, p. 2.)

Lakoff's description of empathy highlights the cognitive and moral dimensions of empathic responses. Empathy "goes to the heart" of real rationality because it involves a consideration of all possible relevant evidence in a consistent and coherent manner. In a similar vein Fricker notes "A hearer with minimal powers of empathy is at a notable disadvantage when it comes to making credibility judgments, for she may often fail to see the speaker's performance in the proper light...Empathy as I take it is an emotional cognitive capacity and entails some well-trained emotions" (Fricker 2007, p. 80).

I take both Lakoff and Fricker to be moving beyond an ordinary conception of empathy as simply "feeling your pain" to recommending the need for training emotions in the service of cognitive capacities. In other words, empathy in the sense they both suggest is not dependent on whether or not one happens to be "naturally" empathic or capable of emotionally resonating with another person. In many contexts where social difference is salient, it may be neither possible nor even fair for an individual to imagine that they could actually feel another's pain. It may not be possible for one person to feel another's pain because their empathic responses are biased toward those they know and who are like them. As in the case of the teachers and parents described above, many of the teachers had little sense of empathy for the lives of the parents of their students. Most were judged by the teachers to be irresponsible or inconsiderate rather than in the midst of trying to juggle multiple pressures and make do with scarce resources.

This is similar to Michael Slote's (2007) point that our sentiments in general and our empathy in particular are often 


\section{Maureen Linker}

affected by distinctions we think are morally irrelevant like race or gender. Slote argues that there is no evidence that this socially biased favoritism is inevitable. Rather, it is likely to be strongly influenced by social, cultural, and familial factors. In addition, such bias has the potential to "fade over time" according to Slote, if an individual has the opportunity to increase their cognitive awareness. Slote makes the distinction between "normal" empathy as a current empirical matter concerning what people in fact do, to a "fully developed empathy" that has gone through a serious educative process thus eliminating unjustified favoritism and bias. Though Slote does not lay out the details of this educative process he does allude to the value of social diversity and the use of varied narrative sources like literature and film to increase our understanding of those whose social experiences are different from our own. Both Fricker and Slote claim that some form of training involving moral, emotional and cognitive educative practices would be the best path to creating a "fully developed empathy."

Yet even a fully developed empathy would not necessarily lead one individual with social privilege to actually feel what it is like to be disadvantaged by the same social hierarchy. While the teachers at Tanglewood had the potential to be better educated about the reality of the lives of the parents, it is not fair to the parents to assume that the teachers could then simply "feel" the parents' pain. The assumption fails to incorporate the complexity of disadvantage and how it is acquired through lived experience, the slow accumulation of indignities over time, and solidarity with others who have been subject to similar experiences.

Thus, by "intellectual empathy" I will mean something along the lines of Slote's "fully developed empathy" in that it is empathy with an emphasis on the integration of moral, emotive, and cognitive capacities. In the case of intellectual empathy these capacities would be focused on interpretation and judgments regarding a speaker's credibility and reliability. The intellectually empathic hearer would be particularly attuned to rhetorical contexts involving social difference and take a speaker's report in such a context to assess the consistency and coherence of their own beliefs and feelings before making an interpretive judgment. In the case of the teachers at Tanglewood, the process would not mean that the teachers simply feel what the students or parents feel but that they recognize the facts of the students' and parents' experiences, what they might feel like, the causes that led to their claims or actions (including the possibility that the teachers might be creating or contributing to the conditions of the students' or parents' disadvantage) and what this data might provide with regard to their own related beliefs and feel- 
ings. The intellectually empathic person seeks to develop empathic responses so as to gain a better ground epistemologically - not only with regard to her own beliefs but with regard to the assessment of evidence more generally. Thus, the objective of intellectual empathy is not to imagine that one can simply feel what another person is feeling but rather that one treat the reports of others, particularly those whose social experiences are vastly different from one's own, as credible sources of information for reflectively assessing one's own system of belief.

\subsection{The principle of intellectual empathy}

If intellectual empathy has this combined emotional, moral and cognitive nature how might we actually train the nonintellectually empathic person to ultimately think in an intellectually empathic way? In the cases outlined above the failures to attend to differences in social privilege and disadvantage meant that evidence was misinterpreted or discounted. I propose that training our reason in the service of intellectual empathy would combine four essential skills. These would include:

(a) Starting from the point of view of mutual compassion.

(b) Recognizing that advantage and disadvantage occur within a matrix of intersecting social properties.

(c) Understanding that social privilege is often invisible to those who have it.

(d) Identifying "Maybe its you" judgments and developing the self-reflective capacity to treat these judgments as opportunities for information and evidence.

I will explain each of the components in turn. My view is that these four features together are necessary to create the kind of interpretive environment where residual prejudice can be recognized, assessed, and adequately diminished. The diminishment of residual prejudice is a key factor in creating not only opportunities for success in a liberal society but also for achieving the kind of reflective and "real rationality" argued for by Lippman, Fricker, and Lakoff.

\section{(a) Mutual compassion}

Mutual Compassion is the normative starting point for intellectual empathy. Mutual compassion entails a commitment to not judging others in simple bivalent categories like "oppressor" or "oppressed" which raise the stakes in an interpretive context. Too often when social differences are examined in a public dialogue, the conversation devolves into guilt, blame, and victimi- 
zation. If we begin with the understanding that no one has a privileged epistemic standpoint with regard to how people are positively or negatively affected by social differences, and that reporting or questioning those differences is a reflection of a sincere desire to gather evidence, then some of the high stakes nature of these dialogues can be minimized.

For instance if a black student in a class of mostly white students reports on her experiences of racism, she has taken a risk. Yet, if a white student in the class has a question or raises a skeptical objection about how the black student interprets her experience, she too takes a risk. The risks are very different. In the first case the black student risks speaking "truth to power" that is naming the ways that racism generally privileges whites and disadvantages blacks in the culture. The black student also risks confirming judgments that whites may have of blacks as "always playing the race card," or "whining or complaining about race" thereby having her credibility undermined. She also risks having to become the authority on the black experience for this group of white students losing her individuality and her identification with other aspects of her social identity.

The white student takes some risks as well albeit of a different sort. First, she risks potentially being perceived by others in the group as a racist for questioning or seeking clarification of her classmate's claim. Secondly, she risks reaffirming the very racist practices at issue if she exercises a kind of privilege in questioning the veracity of the black student's claim. Why would she not simply operate with the default that a claim is credible unless there is a reason to think otherwise? Her questioning implies that there is some reason to think otherwise even if it is simply that it does not correspond with her experiences or her system of beliefs. But questioning in such a context is not simply innocuous, it is loaded with social implications and potentially unfair judgments regarding the one it raises questions.

Establishing mutual compassion as a ground rule means that the stakes are lowered and the risks lessened in contexts where social differences are at issue. This would entail that no one is seen as a spokesperson for all people of their race, their gender, religion, sexual orientation, etc., but rather as an individual reporting their own experiences of social privilege or disadvantage. Mutual compassion would also mean that whenever anyone reports on their experiences around matters of social identity or questions or seeks clarification about those reports, all involved are taking a risk and as such should be given a compassionate hearing. Even in cases where an individual makes a joke, or a side comment that is judged by someone in the context as offensive in some manner, mutual compassion would demand that the interpretation take into account that the 
speaker may have been acting out of a lack of awareness or a lack of information.

A good example of this kind of lack of awareness occurred when U.S. President Barack Obama appeared on a late night talk show and was asked by the host if he had used the White House bowling alley ${ }^{4}$. The President explained both that he had and he was an awkward and incompetent bowler. He then said "I looked like I was bowling in the Special Olympics!" Not surprisingly, the next day families with special needs children and organizations that support both the Special Olympics and people with disabilities were upset by the President's comments. Yet here was a President who was capable of subtle and nuanced race analyses in American society and paid close attention to how race issues are framed in public dialogue. Yet for that moment, physical ability/disability was off his radar. Does this mean the President has a clear negative animus toward the disabled? I think it is reasonable to say that he does not. Rather, disability is not on his radar to the extent that race is, or at least it was not in that moment, and so he said something insensitive. The point to take from the example is that we all have the capacity to let matters fall off our radar, or in some cases, never even have them on our radar in the first place. Mutual compassion means recognizing this fact seeing all players in a dialogue as mutually capable of gaffes or insights around the great variety of social issues. Mutual compassion mandates that we begin with the assumption that we all have something to learn about social difference and that for learning to occur, we have to reduce the high stakes nature of the conversations and be willing to let individuals be our partners in a shared desire to "get it right."

\section{(b) Matrix of intersecting social properties}

The second component of intellectual empathy is the recognition that social identity occurs within a matrix of intersecting social properties.

The term "intersectionality" in terms of social identity, was first coined by feminist legal scholar Kimberly Crenshaw (Crenshaw 1989). Crenshaw argued that the experiences of black women could not be understood by simply adding up the sum of their race and sex. Rather, black women experience their race and their sex in a complex matrix of intersecting factors particular to their social and temporal location. Black women for example do not experience a simple double social disadvantage as women and as blacks. Rather, the intersection of race and

\footnotetext{
${ }^{4}$ The Tonight Show with Jay Leno, March 19, 2009.
} 
gender combine to create conditions that are unique to black women.

The term then gained prominence in the 1990s when sociologist Patricia Hill Collins reintroduced the idea as part of her discussion on black feminism. This term replaced her previously coined expression "black feminist thought", "and increased the general applicability of her theory from African American women to all women" (Mann and Huffman 2005, p. 61). Like Crenshaw, Collins argued that cultural patterns of oppression are not only interrelated, but are bound together and influenced by the intersectional systems of society, such as race, gender, class, and ethnicity (Collins 1990, p. 42).

Research engaging intersectionality can now be found in a wide range of contexts. A survey of recent journal articles includes intersectionality in political geography (Valentine 2007), political science (Hawkesworth 2003), feminist approaches to economics (Brewer et al., 2002), critical psychotherapy (Burman 2004; Fernandes, 2004), sociology (Yuval-Davis 2006), postcolonial studies (Arondecker 2004) and legal studies (Vakulenko 2007; Deckha 2004) to name a few. What draws many theorists to the concept of intersectionality is that it looks to the forms of inequality that are routed through one another rather than reducing advantage and disadvantage to one single cause.

Viewing social properties intersectionally gives a more complex and nuanced characterization of how social identity is experienced. If we think of the struggles of white women during the rise of the feminist movement in the 1960s and 1970s one point of empowerment was how women might "get out of the kitchen and into the workforce!" Of course for black women in the U.S., they had been working for decades in the homes and more specifically in the kitchens of white women. "Getting out of the kitchen and into the labor force" did not have the same resonance for black women as it did for white women. Crenshaw's and Collins' work remind us that if we think in simple monolithic categories we will fail to recognize the unique ways that a confluence of social properties operate together to create identity.

By seeing ourselves, and all those with whom we dialogue and argue as having an intersectional identity, we make room for the unique ways that social advantages and disadvantages can operate in our lives. For instance, if the topic at issue is white privilege it is critical in the discussion to recognize that poor or working class white people will not experience race privilege in the same way that middle class or wealthy whites do. Similarly, whether the white individuals are heterosexual or homosexual or physically able or disabled will make a difference in how they experience social privilege or disadvantage. 
A commitment to seeing identity in intersectional prevents the oversimplified category "lumping" that can sometimes be the default in thinking and reasoning around social issues. Understanding that "all men" or "all homosexuals" or "all Asians" are not real categories of social experience but merely intersecting elements in individual people's complex identities, means that the data can be richer and more relevant to the social issues at hand.

An intersectional framework encourages the voices and perspectives of those who might initially feel alienated or frustrated by discussions of social advantage and disadvantage. A white, working class, Christian male who is struggling to pay his rent and is out of a job may find a discussion of privilege around race and religion to be far from his own experience. His focus may be on the daily struggles he faces in a particularly tough economy. By not recognizing that class and socio-economic status play a role in his social identity, we fail to see the reality of his experiences. Similarly, a wealthy Latina lesbian in the same discussion may feel that while she has experienced social disadvantages in terms of race and sexual orientation, her wealth has nevertheless provided her with advantages that make her experiences very different from poor, lesbian women of color. Both of these individuals play an important role in discussions about social advantage and disadvantage because they typify the complexity of thinking intersectionally and they represent the voices that could easily "check out" of the discussion because it feels too oversimplified.

It is worth saying a word here about the term "disadvantage" since it carries with it clearly negative connotations. The term is problematic since there are circumstances where being at a social disadvantage can provide an individual or a group with advantages from the point of view of critical thinking and evidence gathering. In working with the students at the school described above I discovered that many were quite adept at adding and subtracting money. During the time I worked on the project my own son was in second grade in a well funded, and award winning elementary school in our middle class suburban neighborhood. I occasionally went into my son's class to help out and had a sense of not only his but several of the other students adding and subtracting skills. At the same time, I was working in a second grade at the school district made up of students who were clearly "disadvantaged" in many ways. Yet I noticed that when it came to adding and subtracting numbers and tabulating the exchange of quarters, nickels, dimes and pennies these kids were much further ahead then my son and his classmates. What I asked the teacher she explained that many of the children in her class were already going to the store to buy milk, diapers or 
other essentials for their families. They handled money regularly and knew the value of every coin. My seven year old son, and I expect most of his classmates, did not ever shop for the family or have to handle much money so math questions about the adding and subtracting of coins was new and unfamiliar territory,

Of course I am not suggesting that children should live in poverty or have to shop regularly so that they can become adept at adding and subtracting money! Rather my point is that "disadvantage" like social categories generally, is not a monolithic or uniformly negative concept. To be socially disadvantaged in some ways may mean that you could be advantaged in other ways. Particularly when it comes to evidence about the details and dimensions of the larger social system. This idea can be traced all the way back to Marx and Engels who argued in The German Ideology that members of the working class had epistemic advantages over the middle class and bourgeoisie because they experienced the flaws within the system (Marx and Engels 1846). "Disadvantage" then should be understood like "intersectionality" as a complex and somewhat dynamic term.

Returning to intersectionality, I would also like to add that social advantages and disadvantages should not be seen as identical with personal happiness and unhappiness. Advantages in terms of social properties, (as we shall see in more detail when we turn to the third element of intellectual empathy), are often invisible to those who have them. For that reason, social advantages do not necessarily translate into a feeling of well being, particularly if the individual is wrestling with personal and psychological issues like depression, or addiction, or anxiety. And social disadvantages do not necessarily translate into personal or psychological unhappiness if the individual in question has particularly strong inner fortitude, or a network of supportive family and friends. That is not to deny the documented effects of stress and strain on those who are subjected to racism, sexism, homophobia, etc. (Feagin 1995, Mays 2007). Rather, it is to say that those effects will not be experienced in the same way by every person whose social identity is linked to social disadvantage. For the purposes then of the methodology of intellectual empathy, social advantage and disadvantage will be considered separate and distinct from matters of personal well being and personal suffering.

\section{(c) The invisibility of social privilege}

Sociologist Alan Johnson argues that one of the difficulties with understanding social privilege is that individuals who benefit from it take it as "normal" rather than as a social advantage (Johnson 2001). For example, heterosexual couples who board a 
plane hand in hand, or enter a restaurant arm in arm, generally do not consider their actions to be the result of heterosexual privilege. Rather, their choice to do these things feels "normal." If they choose to display pictures of their partner on their desk at work they don't worry whether or not they will be discriminated against on the basis of their sexual orientation. However for homosexual couples, the same actions can feel far more risky and be fraught with anxiety and frustration. The social privilege and advantages of heterosexuality in our society are not experienced by heterosexuals as advantage but simply "just the way things are." For that reason it is very difficult for those who benefit from social advantage to see it as anything but the status quo. So when groups who experience social disadvantage argue for their rights to be recognized, it can feel to those who are already advantaged that these other groups are seeking "special rights." Yet those seeking equal rights are merely asking for the same rights afforded to those who are socially advantaged. It is particularly tough then trying to get those who enjoy the benefits of the status quo to see that they actually enjoy "special" rights since they are rights not afforded readily to everyone.

In fact being the beneficiary of social advantage carries with it the privilege of remaining oblivious to one's privilege and the disadvantages faced by others. I am not presently physically disabled and if I have to enter a building on campus to run an errand, I never notice whether or not the building or the office are wheelchair accessible. In virtue of my being physically able, the building's accessibility to wheelchairs is not something that would even occur to me to consider. However, if I was in a wheelchair having to run an errand in an unfamiliar place, I would certainly be cognizant of whether or not there were obstacles to my getting to the appropriate destination. And if this building were not accessible to me, I would have to voice my complaints to a powerful group of physically able people who may have never even considered what my experiences might be like. Their lack of consideration need not be the result of their being mean spirited or opposed to the rights of the disabled, but simply the fact that wheelchair accessibility has not shown up on their radar.

Ferri and Gregg (1998) argue that the very definitions of disability imply a failure on the part of the disabled to meet socially created and imposed "able-bodied" standards. Conceptions of disability, as a minority status that fails to live up to the standards of "normalcy," perpetuate the belief that adaptations required by individuals with disabilities are "special" and "restrictive" rather than universal accommodations for conditions all humans could potentially face. Equality for the disabled could never be achieved, according to the authors, because do- 
ing so would require conforming to the norms of the society that created the disability in the first place. Disability must always exist on the margins because it is defined in relationship to ability, which exists at the center.

It follows that many stunted or abandoned arguments around social issues hinge on how those who are advantaged hear those who are disadvantaged. If, as in the hypothetical case I just presented, I voiced my complaint to the building's designer or manager, my complaint could easily be met with defensiveness. To have your privilege pointed out to you as well as your ignorance of who is disadvantaged, particularly when you have not felt it as privilege, can feel like you did something wrong without even knowing it. It is not a surprise then that when groups of people with differing social advantages and disadvantages come together around social issues, some members feel frustrated at having to teach others and some members feel frustrated at having to be taught.

If we begin from a position of intellectual empathy, we start with a mutually compassionate standpoint and an understanding that social identity is complex and intersectional and not identical with personal happiness and unhappiness. In addition, we can now add our third element. Social advantage is generally not experienced as advantage by those who have it. We should expect that those who benefit from social advantage, will often be surprised to find out that they are in fact the recipients of social benefits since the experience simply feels "normal" to them.

At the same time, we should expect that those who voice their experiences of social disadvantage will be heard by those who benefit in some ways socially as being "whiners," or "complainers," or "playing the race card," "the gender card," etc.. For that reason, it is crucial that room be made in the dialogue for a non-defensive hearing of the data. The default should be in favor of data from those who are experiencing harms in the social and cultural framework. Not because there isn't a possibility that someone may be simply whining or complaining or playing a race, gender, religion card, but because the probability is that they are not (because we assume people are giving credible reports unless there is a reason to think otherwise) and we do not want to lose significant information about the social fabric.

For instance, Muslim students on my campus requested a prayer room since many students are on campus for ten to twelve hours a day and as Muslims, are required to pray five times a day. Initially non-Muslim students on campus, who are mostly Christian, responded by arguing that Muslim students were seeking religious privileges from a state funded school and as such, their request was unconstitutional. Further, those op- 
posed argued that Christian students do not get special rights and there is no prayer room that would be analogous to the Muslim prayer room. The privileges that Christian students experienced as students was seemingly invisible in the discussion. The fact that the university was closed on Christmas for example, was deemed simply "normal." The fact that a Christian student group had a meeting room on campus for weekly prayer and that the room was heated and kept lit by the university during use was not seen as a constitutional violation. It was seen instead as meeting the needs of "our" community. Yet when Muslim students sought similar accommodations, though they required use of the room multiple times daily, it was seen as a constitutional violation. The crucial element missing in the debate for the Christian students who were opposed was hearing what life was like for Muslim students on campus. As one young woman put it, "though I am a citizen of this country and a student at this campus you are making me feel like this is your country and your university and not mine or ours." Yet what I have seen following the successful resolve of this controversy (the "reflection room" exists as a space for Muslim students to engage in daily prayer) non-Muslim students have much more data around the issue of religious rituals, what separation of church and state really amounts to, and some of the specifics about being Muslim in America. By making privilege visible, and disadvantage credible, we maximize the standards for good critical thinking. By incorporating aspects of social location, social advantage and disadvantage we allow the standards of good critical thinking to be more fully realized. The elimination of bias and stereotypical thinking, the furthering of consistency, coherence, parity of reasoning and analogical reasoning are all better realized when we provide a systematic way to make room for social standpoint in rhetorical contexts.

(d) Identifying "Maybe it's you" judgments as self-reflective opportunities

The final element in the methodology of intellectual empathy is paying attention to "maybe it's you" judgments. By "maybe it's you" judgments I mean those judgments around social issues that come packaged as a judgment of a claimant as simply "complaining," "whining," "playing the race," "gender," etc card. It is a dismissal of the credibility of a speaker's claim because the interpreter is somehow sick of hearing it or because they think it is a personal issue and not a social issue. So for instance, if a young black male is explaining to a group of his classmates that he is often pulled over in white neighborhoods simply for "driving while black" his claim may be considered 


\section{Maureen Linker}

suspect by white students in the class with the accompanying thought; "no buddy, it might just be that you are a bad driver!" Now while that could be true there should be a presumption in favor or the black student's claim just as there should be a presumption in favor of any person's claim provided it is not inconsistent with the hearer's experiences and background beliefs and the claimant does not have a history of unreliability or dishonesty. Given that the black student in question did not violate any of the conditions for credibility, why the rush to skepticism? It may be that for white students, if they have neither experienced racial discrimination from the police nor been exposed to the history of police officers profiling black men, their assumption would be that you only get pulled over for the things that you do as an individual. While they could believe that the black student was pulled over, and that he believes it was because he was black, their judgment is that he is mistaken as to the reasons for why he was pulled over.

If the black student insists that he has experienced a pattern of this kind of racial profiling and discrimination it could be easy enough for the white students in question to begin to turn off. They might do this by just letting go of the conversation and judging the black student to be race obsessed or they could counter by undermining his judgment and presenting their experiences as counter evidence. What is significant though from the point of view of interpretation and critical thinking is that the white students are not allowing themselves to listen to the data. Why are they so resistant to the black student's claims? What would it mean if he was right?

The defensive reaction described in (c) around admitting social privilege often works itself into judgments of others as lacking credibility. Yet it is often around those topics for which we have the most to learn that we react with a defensive and stubborn posture. By shifting an individual away from a social analysis to individual blame, those with social advantage continue to benefit. When Betty Friedan wrote about "the problem that has no name" in The Feminine Mystique (1963), she was describing a pervasive social problem facing disaffected post war women who felt their unhappiness was simply their own fault. Rather than examining the social and structural components that limited women's choices in the post war years many women were made to feel like they were failing as women since they were not happy just being wives or mothers. When women argued that they were frustrated because of gender discrimination, they were often met with skepticism and told that it was probably a result of their own behavior. Yet as they continued to insist, they were charged with being rabid feminists who could never think of anything besides women's issues. Their objec- 
tions were clearly judged as "maybe it's just you" moments for many men.

If we take into account how difficult it is to see social privilege we can combine it with the fact that it is also difficult to hear about social disadvantage and discrimination, especially if it is perpetrated by the groups to which we belong. Yet it is in just those circumstances that significant data could be available to help us through logical impasses. The fourth element in the methodology of intellectual empathy is being attuned to our tendency to shut down or raise a skeptical "maybe it's you" objection which can get in the way of relevant data. In other words "maybe it's you" could more likely be "maybe it's me" and then the question arises as to why it is so difficult for me to believe the claims of someone who is reporting on the social problems they face.

Again, this is not to say that it is never the case that "it may be you" is actually the right judgment to make. What this fourth element of intellectual empathy demands, is that the "maybe it's you" judgment be a last resort after giving a fair hearing to the individual's claims and seeking out any relevant data that might support or corroborate those claims.

\section{Conclusion}

I have tried to show in this essay what a lack of intellectual empathy looks like in a variety of actual cases starting with an elementary classroom but extending to a wider variety of rhetorical contexts. My objective has been to demonstrate the need for incorporating aspects of social identity theory and power relations into informal logic theory more generally. It is because of the "residual prejudice" noted by Fricker, that interpretation and judgment can break down in the context of social differences. If we trained students to pay close attention to how it is possible for anyone to inadvertently be insensitive to social differences, to think of their own and others' identity as intersectional and complex, to be aware that social advantage is hard to see and to work to see it, and finally to red flag "maybe it's you" judgments as opportunities for self-reflection then some of the failures in the cases cited above could instead be opportunities for more rigorous, reflective thinking.

Similarly, by framing these principles around best practices for effective reasoning we can make evident how matters of social injustice are often failures of critical thinking. Much of the work that has already been done in informal logic theory on fallacies, testimony, credibility, and interpretive context could be brought to bear on social theory. Inequality and injustice ex- 
ist not simply because people are intentionally biased but because they are often unreflectively biased. Intellectual empathy is a path to self-reflection drawing from the combined strengths of informal logic and social theory.

By starting from the point of view of intellectual empathy we can take some first steps toward remedying the kind of problems that Lippman, Fricker, and Lakoff characterized as existing both within our classrooms and our general discourse. Alongside other elements of good critical thinking, social difference theory and the cognitive and moral components of intellectual empathy should stand as well so as to further the study of informal logic and the practical problems of bias and prejudice when reasoning in contexts of social difference.

Acknowledgements: I would like to express my sincere thanks to Deborah Smith Pollard, Gloria House, Lora Lempert, Christopher Burke and two anonymous reviewers of this journal for their thoughtful and challenging comments on earlier drafts of this paper.

\section{References}

Adams, M. (Ed.) (2000). Readings for Diversity and Social Justice. New York: Routledge.

Anderson, S.K. and Middleton, V. (Eds.). (2010). Explorations in Diversity: Examining Privilege and Oppression in a Multicultural Society. Belmont, CA: Brooks/Cole.

Burke, C., Adler, M. and Linker, M. (2007). "Where Interaction Leads to Higher Standards: Policy Suggestions for a Humanizing Pedagogy" Multicultural Perspectives in Education, 17:2: 199-208.

Burman, E. (2004). "From Difference to Intersectionality: Challenges and Resources." European Journal of Psychotherapy Counseling and Health 6: 293-308.

Brewer, M.B. and Roccas, S. (2002). "Social Identity Complexity." Personality and Social Psychology 6: 88-106.

Collins, P.H. (1990). Black Feminist Thought: Knowledge, Consciousness, and the Politics of Empowerment. London. Harper Collins Academic.

Crenshaw, K. (1989). "DeMarginalizing the Intersection of Race and Sex: A Black Feminist Critique of Antidiscrimination Doctrine, Feminist Theory and Antiracist Politics." In University of Chicago Legal Forum: Feminism in the Law: Theory, Practice, and Criticism (pp. 139-167). Chicago: University of Chicago Press. 
Crenshaw, K., Gotanda, N., Peller, and G., Kendall, T. (1995). Critical Race Theory: The Key Writings that Formed the Movement, New York: NY Press.

Feagin, J. and Sikes, M. (1995). Living with Racism: The Black Middle Class Experience. Boston: Beacon Press.

Ferri, B. and Gregg, N. (1998). "Women with Disabilities: Missing Voices" Women's Studies International Forum 21: 429-439.

Fricker, M. (2007). Epistemic Injustice: Power and the Ethics of Knowing. Oxford: Oxford University Press.

Friedan, B. (1963). The Feminine Mystique, New York: Norton $\&$ Co.

Hawkesworth, M. (2003). "Congressional Enactments of RaceGender: Toward a Theory of Raced-Gendered Institutions." American Political Science Review 97: 529-550.

Hooks, B. (2009). Teaching Critical Thinking: Practical Wisdom. New York: Routledge.

Johnson, A. (2001). Privilege, Power, and Difference. Mountain View CA: Mayfield Publishing.

Lakoff, G. (2009). "Empathy, Sotomayor, and Democracy: The Conservative Stealth Agenda" in Huffington Post, May 30, 2009.

http://www.huffingtonpost.com/george-lakoff/empathysotomayor-and-dem b 209406.html.

Linker, M. (2003). "Why Should Ideal Reasoners Become Evil Computers?" Science as Culture, 12(4): pp. 547-555.

Linker, M. (2001) "Epistemic Relativism and Socially Responsible Realism: Why Sokal is Not an Ally in the Science Wars" Social Epistemology: A Journal of Knowledge, Culture, and Policy 15(1): 59-79.

Lippman, M. (2003). Thinking in Education. Cambridge: Cambridge University Press.

Mann, S.A and Huffman D. (2005). "The Decentering of Second Wave Feminism and the Rise of the Third Wave". Science and Society, 69(1): 56-91.

Marx, K. and F. Engels. (1998). The German Ideology. Amherst: Prometheus Books. (First publication, 1846.)

Mays, V., Cochran S. and Barnes N. (2007). "Race, Race Based Discrimination, and Health Outcomes Among African Americans." Annual Review of Psychology 58: 201-225.

Mizra, H. (2009). "Postcolonial Subjects, Black Feminism and the Intersectionality of Race and Gender in Higher Education." In Roland Sintos Coloma (Ed.), Postcolonial Challenges in Education Counterpoints: Studies in the Postmodern Theory of Education, (pp. 233-248). New York: Peter Lang. 
McIntosh, P. (1988). "White Privilege and Male Privilege: A Personal Account of Coming to See Correspondences Through Work in Women's Studies." Working Paper \#189 by Peggy McIntosh. Wellesley College Center for Research on Women.

Parks, F.R. and Kennedy, J.H. (2007). "The Impact of Race, Physical Attractiveness, and Gender on Education Majors' and Teachers' Perceptions of Student Competence." Journal of Black Studies 37: 936-943.

Slote, M. (2007). The Ethics of Care and Empathy. Oxford: Routledge.

Vakulenko, A. (2007). "Islamic Dress in Human Rights Jurisprudence: A critique of current trends." Human Rights Law Review 7: 717-739. Oxford: Oxford University Press.

Valentine, G. (2007). "Theorizing and Researching Intersectionality: A Challenge for Feminist Geography." The Professional Geographer 59: 10-21.

Wise, T. (2004). White Like Me: Reflections on Race from a Privileged Son. Berkeley, CA: Soft Shell Press.

Young, M.I. (1992). "Five Faces of Oppression." In Thomas E. Wartenburg (Ed.), Rethinking Power. Albany, NY: State University of New York Press.

Yuval-Davis, N. (2006). "Intersectionality and Feminist Politics." European Journal of Womens Studies 13: 193-210. 